\title{
Efeito da presença da folha no enraizamento de estacas semilenhosas de porta-enxertos de videira
}

\author{
Effect of leaf presence on semihardwood cutting rooting of grapevine rootstocks
}

Ivan Bordin $^{1}$ Paulo Cesar Hidalgo ${ }^{2}$ Rodrigo Bürkle ${ }^{3}$ Sérgio Ruffo Roberto ${ }^{4}$

\section{- NOTA -}

\section{RESUMO}

O objetivo deste trabalho foi estudar o enraizamento de estacas semilenhosas de porta-enxertos de videira IAC 766 e IAC 572 em câmara de nebulização. Para cada um dos porta-enxertos, foram estudados três tipos de estacas: com folha inteira, com meia folha e sem folha. $O$ delineamento experimental utilizado foi o inteiramente casualizado em esquema fatorial $2 \times 3$ (2 porta-enxertos e 3 tipos de estacas), com cinco repetições e 10 estacas por parcela. Os dados foram submetidos à análise de variância e ao teste Tukey a $5 \%$ de probabilidade. Para a técnica de propagação por estacas semilenhosas, o porta-enxerto IAC 572 apresentou melhor capacidade de enraizamento que o IAC 766. A presença da folha em estacas semilenhosas de porta-enxertos de videira foi essencial para a formação de raízes adventícias.

Palavras-chave: uva, propagação, raiz.

\section{ABSTRACT}

The objective of this experiment was to study the rooting of semihardwood cuttings of the grapevine rootstocks IAC 766 and IAC 572, in mist chamber condition. For each rootstock, three types of cuttings were evaluated: with leaf, with half leaf, and without leaf. A randomized design was used as experimental model in a 2-factor arrangement (2 rootstocks genotypes and 3 types of cuttings), with five replications and 10 cuttings per plot. The results were evaluated by variance ana byssi and Tukey test with $5 \%$ of probability. The rootstock IAC 572 showed better rooting than IAC 766. The leaf presence in semihardwood cuttings of grapevine was essential for adventicious root formation.

Key words: grape, propagation, root.

O processo de produção de mudas de videira predominante, no Brasil, é o plantio direto no campo ou em recipientes, utilizando estacas lenhosas do portaenxerto, obtidas durante o fim do período de repouso hibernal de ramos maduros lignificados, sendo a melhor época para a estaquia os meses de junho a agosto (SOUSA, 1996). O uso de estacas lenhosas tem a limitação de época de coleta, da quantidade do material propagativo, além da possibilidade de propagar viroses e de falhas no campo com posterior replante que pode desuniformizar o parreiral. Algumas espécies de difícil enraizamento como Vitis berlandieri, Vitis cinerea e videiras muscadíneas (Vitis rotundifolia), são de difícil propagação via estaquia.

A técnica de propagação por estacas semilenhosas permite a obtenção de material propagativo livre de vírus de forma rápida e em grande quantidade em diferentes épocas do ano, a partir de

\footnotetext{
${ }^{1}$ Engenheiro Agrônomo, Doutorando em Agronomia, Área de Concentração em Fitotecnia, Universidade Estadual de Londrina (UEL), CP 6001, 86051-990, Londrina, PR. E-mail: ivanbordin@uel.br.

${ }^{2}$ Engenheiro Agrônomo, Mestrando Agronomia, Área de Concentração em Solos, UEL.

${ }^{3}$ Engenheiro Agrônomo, Mestre em Agronomia, Área de Concentração em Fitotecnia, UEL.

${ }^{4}$ Engenheiro Agrônomo, Doutor em Fruticultura, Professor Adjunto, Departamento de Agronomia, UEL. E-mail: sroberto@uel.br. Autor para correspondência.
} 
poucas matrizes. Este processo pode ser utilizado quando se dispõe de pouco material vegetativo ou quando o sistema de produção de mudas envolve a enxertia verde, que consiste na união do garfo com um porta-enxerto de mesma consistência (ANACLERIO et al., 1992). A presença da folha, por ser fonte de auxina, é um importante fator na promoção do enraizamento de estacas semilenhosas de diversas espécies frutíferas. Este hormônio é translocado para a base das estacas e, ao induzir a formação de raízes, permite a produção de carboidratos através da fotossíntese pela planta (HARTMANN et al., 1990). Entretanto, espécies com folhas grandes podem apresentar dificuldade no enraizamento pela desidratação excessiva dessas folhas.

O objetivo do trabalho foi avaliar a influência da presença da folha no enraizamento de estacas semilenhosas dos porta-enxertos IAC 572 e IAC 766 em câmara de nebulização.

O experimento foi realizado sob cultivo protegido nos meses de abril/maio de 2003 na Universidade Estadual de Londrina - UEL. As plantas matrizes das quais foram retiradas as estacas pertencem ao Banco de Germoplasma de Videiras da UEL, sendo selecionados os porta-enxertos IAC 766 e IAC 572, com dois anos de idade, cultivados em Latossolo Vermelho distroférrico de textura argilosa. Foram selecionados ramos do ano com bom desenvolvimento para obtenção das estacas semilenhosas com 12 a 14 cm de comprimento, que tiveram um corte horizontal abaixo do primeiro nó após a retirada da gema desta posição e um corte em bisel acima do nó superior. Foram preparadas três tipos de estacas: com a folha inteira, com meia folha e sem folha. Os recipientes adotados para o enraizamento foram bandejas plásticas, preenchidas com casca de arroz carbonizada, que foram dispostas em câmara de nebulização intermitente (ligada por cinco segundos em intervalos de $10 \mathrm{~min}$ ), com cobertura de sombrite $50 \%$. O controle de doenças fúngicas foi realizado com pulverizações semanais de solução de benomyl a 1\%. O delineamento experimental utilizado foi inteiramente casualizado em esquema fatorial $2 \times 3$ (dois porta-enxertos e três tipos de estacas), com cinco repetições, sendo cada parcela composta por 10 estacas.

Após 35 dias, foram avaliadas as seguintes variáveis: porcentagem de estacas enraizadas, porcentagem de estacas mortas, porcentagem de estacas não enraizadas com calo, porcentagem de estacas com folhas remanescentes, número de raízes por estaca, comprimento de raízes por estaca $(\mathrm{cm})$, matéria fresca das raízes por estaca (g) e matéria seca das raízes por estaca (g), sendo esta última variável avaliada após secagem das raízes por $48 \mathrm{~h}$ a $68^{\circ} \mathrm{C}$ em estufa de ventilação forçada (ROBERTO et al., 2004). Os dados foram submetidos à análise de variância e ao teste Tukey em 5\% de probabilidade.

Na tabela 1, estão as variáveis que não apresentaram interação significativa entre os porta-

Tabela 1 - Análise de variância das médias da porcentagem de estacas enraizadas (PEE), porcentagem de estacas não enraizadas com calo (PEC), número de raízes por estaca (NRE), matéria fresca das raízes por estaca (MFR) e comprimento de raízes por estacas (CRE) dos porta-enxertos IAC 766 e IAC 572, propagados por estacas semilenhosas, com a folha inteira (FI), com meia folha (MF) e sem a folha (SF).

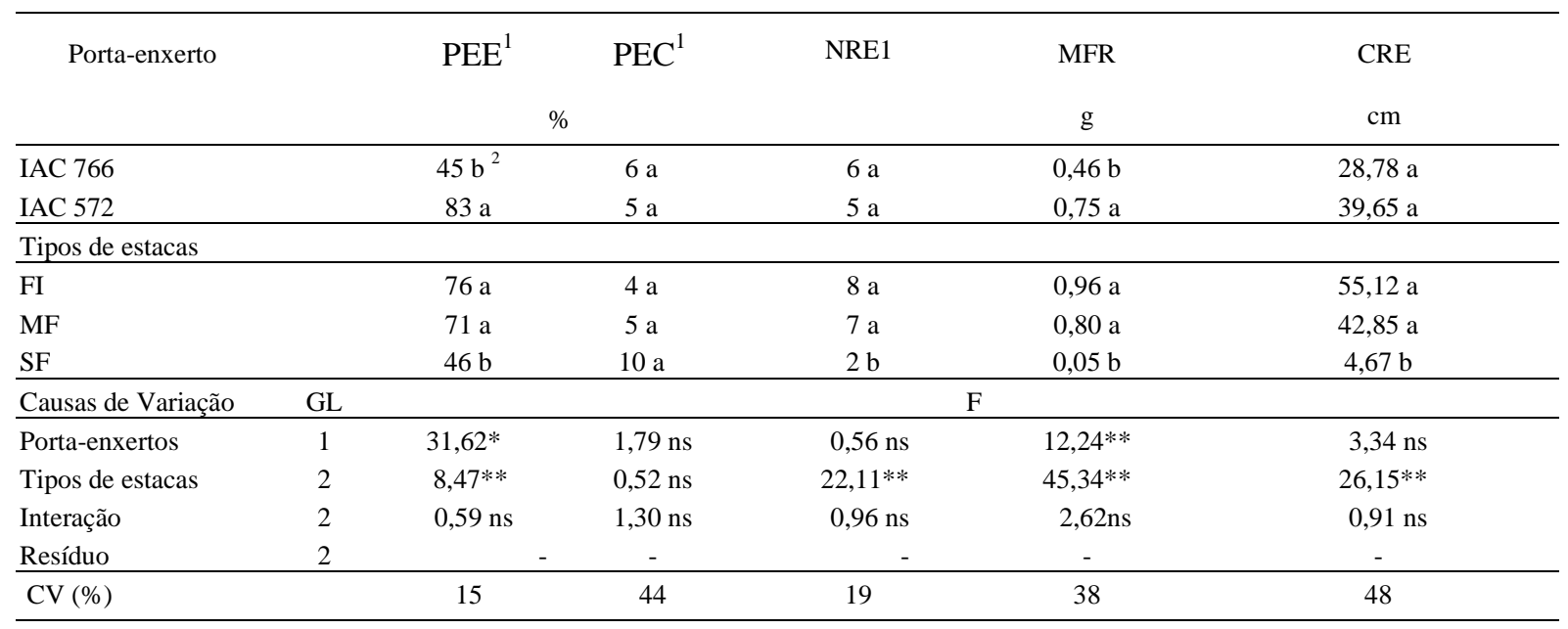

\footnotetext{
${ }^{1}$ Dados transformados em $\sqrt{\mathrm{x}+0,5}$.

${ }^{2}$ Médias seguidas de mesma letra na coluna não diferem entre si pelo teste Tukey.

ns = não significativo. $* *$ = significativo a $1 \%$ * = significativo a $5 \%$.
}

Ciência Rural, v.35, n.1, jan-fev, 2005. 
enxertos e os tipos de estacas. O porta-enxerto IAC 572 foi superior ao IAC 766 em relação à porcentagem de estacas enraizadas e à matéria fresca das raízes por estaca, não se diferenciando quanto à porcentagem de estacas não enraizadas com calo, número de raízes por estaca e comprimento de raízes por estacas. Pode-se observar que o IAC 766, apesar de ter um baixo enraizamento (45\%) comparativamente ao IAC 572 (83\%) e menor matéria fresca de raízes, conseguiu compensar esta desvantagem emitindo um número equivalente de raízes mais finas e igualando-se no comprimento radicular (Tabela 1). BIASI et al. (1997) encontraram resultados diferentes, constatando que não houve diferença entre a porcentagem de estacas enraizadas e a matéria fresca de raízes, enquanto o número de raízes por estaca do porta-enxerto IAC 766 foi superior ao IAC 572. Respostas diferenciadas entre cultivares, quanto à capacidade de formar raízes adventícias em estacas, têm sido relatadas por outros autores, sendo umas das principais explicações para este comportamento a constituição genética das cultivares que resultaria em um potencial de enraizamento diferenciado entre elas (DUTRA et al., 1998). O sucesso do enraizamento de estacas semilenhosas se deve à tendência destas estacas de enraizar com mais facilidade, pois apresentam tecidos mais tenros, não havendo conseqüentemente, a presença de um anel de esclerênquima altamente lignificado, que dificultaria a emissão dos primórdios radiculares (FACHINELLO et al. 1995).

Para as variáveis referentes à presença da folha, as estacas com folha inteira e com meia folha foram superiores às estacas sem folha quanto à porcentagem de estacas enraizadas, ao número de raízes por estaca, à matéria fresca de raízes por estaca e ao comprimento de raízes por estaca, o mesmo não ocorrendo para a porcentagem de estacas não enraizadas com calos (Tabela 1). A falta de interação significativa para a porcentagem de estacas não enraizadas com calos pode estar relacionado ao fato de que este processo é independente da formação de raízes, podendo ou não resultar na emissão das mesmas (FACHINELLO et al., 1995). PACHECO et al. (1998) demonstraram que a formação de raízes não ocorreu diretamente do calo no enraizamento da videira Muscadínea (V. rotundifolia).

Ao avaliarem o aumento da área foliar em estacas semilenhosas de porta-enxertos de videira, BIASI et al. (1997) constataram que o enraizamento aumentou com o acréscimo de $25 \%$ da área foliar, não se diferenciando do maior tratamento com $100 \%$ de área foliar, enquanto o número de raízes por estaca aumentou até $92 \%$ da área foliar e a matéria seca de raízes demonstrou resposta linear. O efeito benéfico da presença das folhas em estacas semilenhosas para o enraizamento é atribuído à produção de auxinas e cofatores, que são transportados para a base das estacas e pela continuação do processo da fotossíntese, responsável pela síntese de carboidratos necessários como fonte de energia para formação e crescimento das raízes (DAVIS, 1988).

Na tabela 2, estão as variáveis que apresentaram interação significativa entre os portaenxertos e os tipos de estacas. A porcentagem de estacas com folhas remanescente e a matéria seca de raízes por estaca do porta-enxerto IAC 572 superou o IAC 766 para os tratamentos com folha inteira e com meia folha, não ocorrendo diferença na ausência da folha (Tabela 2). O porta-enxerto IAC 572 apresentou menor porcentagem de estacas mortas que o IAC 766 para os tratamentos com folha inteira e meia folha, não ocorrendo diferença com a ausência da folha. Estes resultados diferem dos obtidos por BIASI, et al (1997),

Tabela 2 - Porcentagem de estacas mortas, porcentagem de estacas com folhas remanescentes e matéria seca de raízes por estaca dos porta-enxertos IAC 766 e IAC propagados por estacas semilenhosas com a folha inteira (FI), com meia folha (MF) e sem a folha (SF).

\begin{tabular}{|c|c|c|c|c|}
\hline \multirow{2}{*}{$\begin{array}{l}\text { Porta- } \\
\text { enxerto }\end{array}$} & \multicolumn{3}{|c|}{ Tipos de estacas } & \multirow[b]{2}{*}{$\mathrm{F}$} \\
\hline & FI & MF & SF & \\
\hline \multicolumn{5}{|c|}{ Porcentagem de estacas mortas ${ }^{1}$} \\
\hline IAC 766 & $36 \mathrm{Aa}^{2}$ & $47 \mathrm{Aa}$ & 54 Аа & $1,75 \mathrm{~ns}$ \\
\hline IAC 572 & $4 \mathrm{Bb}$ & $2 \mathrm{Bb}$ & $34 \mathrm{Aa}$ & $16,19 * *$ \\
\hline$F$ & $22,73 * *$ & $42,64 * *$ & 3,62 ns & - \\
\hline CV (\%) & \multicolumn{4}{|c|}{20} \\
\hline \multicolumn{5}{|c|}{ Porcentagem de folhas remanescentes ${ }^{1}$} \\
\hline IAC 766 & $12 \mathrm{Ba}$ & $6 \mathrm{Ba}$ & $0 \mathrm{Ab}$ & $6,5 * *$ \\
\hline IAC 572 & $68 \mathrm{Aa}$ & $74 \mathrm{Aa}$ & $0 \mathrm{Ab}$ & $115,73^{* *}$ \\
\hline $\mathrm{F}$ & $83,65 * *$ & $133,68 * *$ & $0 \mathrm{~ns}$ & - \\
\hline CV (\%) & \multicolumn{4}{|c|}{17} \\
\hline \multicolumn{5}{|c|}{ Matéria seca das raízes por estaca (g) } \\
\hline IAC 766 & 0,052 Ba & $0,028 \mathrm{Bb}$ & $0,004 \mathrm{Ab}$ & $12,13 * *$ \\
\hline IAC 572 & $0,070 \mathrm{Aa}$ & $0,078 \mathrm{Aa}$ & $0,004 \mathrm{Ab}$ & $38,34 * *$ \\
\hline$F$ & $6,7 *$ & $31,85 * *$ & $0,067 \mathrm{~ns}$ & - \\
\hline CV (\%) & \multicolumn{4}{|c|}{38,7} \\
\hline
\end{tabular}

${ }^{1}$ Dados transformados em $\sqrt{\mathrm{x}+0,5}$.

${ }^{2}$ Médias seguidas das mesmas letras maiúsculas nas colunas e minúsculas nas linhas não diferem entre si pelo teste Tukey. ns = não significativo. ${ }^{* *}=$ significativo a $1 \%$. $*$ significativo a $5 \%$. 
que encontrou comportamento semelhante dos dois porta-enxertos em relação à área foliar, com 50\% de mortalidade na ausência da folha e $100 \%$ de enraizamento com área foliar total. A alta porcentagem de estacas mortas apresentado pelo IAC 766 ocasionou a falta de interação entre os tratamentos referentes à presença da folha (Tabela 2). Este fato pode ser explicado pelo estado fitossanitário da planta matriz, que apresentava pequenas manchas provenientes de ataque fúngico, que podem ter influenciado na baixa porcentagem de folhas remanescentes e, conseqüentemente, elevada morte de estacas. Segundo FACHINELLO et al. (1995), a sanidade da planta matriz pode ocasionar a morte das estacas antes ou após a formação das raízes, podendo afetar sua sobrevivência ou a qualidade do sistema radicular da muda.

Conclui-se que, para a técnica de propagação por estacas semilenhosas em câmara de nebulização, o porta-enxerto IAC 572 apresenta melhor capacidade de enraizamento que o IAC 766, e a presença da folha em estacas semilenhosas de portaenxertos de videira é essencial para a formação de raízes adventícias.

\section{REFERÊNCIAS BIBLIOGRÁFICAS}

ANACLERIO, F. et al. Il miglioramento qualitativo delle produzioni vivaistiche. Vignevini, Bologna, v.11, p.43-46, jan-mar, 1992

BIASI, L.A. et al. Propagação de porta enxertos de videira mediante estaquia lenhosa. Bragantia, Campinas, v.56, n.2, p.1-14, fev, 1997.

DAVIS, T.D. Photosynthesis during adventitious rooting. In DAVIS, T.D. et al. Adventitious root formation in cuttings. Portland : Dioscorides, 1988. Cap.16, p.214-234.

DUTRA, L.F. et al. Efeito da aplicação de ethefon em ameixeira (Prunus salicina Lindl) e do IBA no enraizamento de suas estacas. Scientia Agricola, Piracicaba, v.55, n.2, p.296-304, mai-ago, 1998.

FACHINELLO, J.C. et al. Propagação de plantas frutíferas de clima temperado. Pelotas : UFPEL, 1995. 178p.

HARTMANN, H.T. et al. Plant propagation: principles and practices. New Jersey : Prentice Hall, 1990. 647p.

PACHECO, A.C. et al. Aspectos anatômicos do enraizamento da videira muscadínia (Vitis rotundifolia Michx) através de alporquia. Scientia Agricola, Piracicaba, v.55, n.2, p.210-217, mai-ago, 1998.

ROBERTO, S.R. et al. Produção de mudas de videira Itália através de enxertia verde em porta-enxertos propagados por estacas herbáceas. Revista Brasileira de Fruticultura, Jaboticabal, v.26, n.1, p.127-130, jan-abr, 2004.

SOUSA, J.S.I. Uvas para o Brasil. Piracicaba : FEALQ, 1996. 791p.

Ciência Rural, v.35, n.1, jan-fev, 2005. 